\title{
Functional carbons and carbon nanohybrids for the catalytic conversion of biomass to renewable chemicals in the condensed phase
}

\author{
John Matthiesen a,c, Thomas Hoffa, Chi Liu a,b, Charles Pueschel c, Radhika Rao a,b, \\ Jean-Philippe Tessonnier a,b,c,* \\ a Department of Chemical \& Biological Engineering, Iowa State University, Ames, IA 50011, USA \\ ${ }^{\mathrm{b}}$ NSF-ERC Center for Biorenewable Chemicals (CBiRC), Ames, IA 50011, USA \\ c US Department of Energy Ames Laboratory, Ames, IA 50011, USA
}

A R T I C L E I N F O

\section{Article history:}

Received 15 April 2014

Accepted 25 April 2014

Published 20 June 2014

\section{Keywords:}

Biomass conversion

Renewable chemicals

Heterogeneous catalysis

Carbon nanotubes

Graphene

\begin{abstract}
A B S T R A C T
The production of chemicals from lignocellulosic biomass provides opportunities to synthesize chemicals with new functionalities and grow a more sustainable chemical industry. However, new challenges emerge as research transitions from petrochemistry to biorenewable chemistry. Compared to petrochemisty, the selective conversion of biomass-derived carbohydrates requires most catalytic reactions to take place at low temperatures $\left(<300^{\circ} \mathrm{C}\right)$ and in the condensed phase to prevent reactants and products from degrading. The stability of heterogeneous catalysts in liquid water above the normal boiling point represents one of the major challenges to overcome. Herein, we review some of the latest advances in the field with an emphasis on the role of carbon materials and carbon nanohybrids in addressing this challenge.
\end{abstract}

(C) 2014, Dalian Institute of Chemical Physics, Chinese Academy of Sciences. Published by Elsevier B.V. All rights reserved.

\section{Introduction}

The production of chemicals from renewables receives growing attention due to declining fossil resources and the aspiration for a more sustainable chemical industry. It is now widely acknowledged that lignocellulosic biomass will play a central role when transitioning from petroleum to renewables as a feedstock. Carbohydrates represent the largest fraction in biomass and most current research efforts focus on their selective conversion to desired platform chemicals [1]. It has already been established that heterogeneous catalysis represents a key technology to convert carbohydrates into biorenewable chemicals with a high selectivity. However, several new challenges emerge as research progresses [2]. While many petrochemical reactions are carried out at high temperature and in the gas phase, carbohydrates obtained from lignocellulosic biomass easily degrade under these conditions to form anhydrosugars, carboxylic acids, and furanics [3]. In this regard, a progressive transition from petrochemistry to biorenewable chemistry entails a paradigm shift. Now, most reactions take place in the condensed phase. Green solvents such as water and alcohols lead to more sustainable processes, but create new constrains in terms of catalyst stability. The latter became apparent when investigating the transesterification of triglycerides to produce first generation biodiesel. This reaction is catalyzed both by solid acids and bases. A variety of metal oxide catalysts have been investigated including sulfated zirconia, alkali ion-exchanged zeolites, alkaline earth metal oxides, clays such as hydrotalcite, and perovskite-type mixed oxides $\left(\mathrm{CaTiO}_{3}, \mathrm{CaMnO}_{3}\right.$, $\mathrm{CaZrO}_{3}$ ) [4-7]. Most oxides were found to deactivate within 10

* Corresponding author. Tel: +1-515-294-4595; E-mail: tesso@iastate.edu DOI: 10.1016/S1872-2067(14)60122-4 | http://www.sciencedirect.com/science/journal/18722067 | Chin. J. Catal., Vol. 35, No. 6, June 2014 
$\mathrm{h}$ at $60^{\circ} \mathrm{C}$ due to the strong adsorption of the fatty acid and the partial dissolution of the catalyst under reaction conditions. Deactivation due to leaching of the active species in the solution was particularly severe for solid Lewis bases as polar compounds such as methanol and glycerol easily extract alkaline earth ions from the oxide structure [4,5]. For example, ETS-10 lost $45 \%$ of its original alkali content $(\mathrm{Na}, \mathrm{K})$ within $10 \mathrm{~h}$ [4].

Oxides suffer from similar deactivation in water, which is the green solvent of choice for the conversion of lignocellulosic biomass to fuels and chemicals. Water is abundant, cheap, and it dissolves polar oxygenates found in this feedstock [8]. Water was demonstrated to be a good medium for the depolymerization of cellulose, the dehydration of fructose to 5-hydroxymethylfurfural (5-HMF), and for aqueous phase reforming [9-13]. Therefore, it seems natural to study the stability of desired catalysts under conditions relevant to the target reactions, i.e. $100{ }^{\circ} \mathrm{C}<T<250{ }^{\circ} \mathrm{C}$ and $P^{*}{ }_{\mathrm{H} 2 \mathrm{O}}(T)<P<100$ bar. Surprisingly, in-depth investigations on changes in surface chemistry, structure (phase transition), and chemical composition are fairly recent [8,14-18].

The hydrothermal stability of $\gamma-\mathrm{Al}_{2} \mathrm{O}_{3}$, a support used for the aqueous phase reforming of biomass-derived oxygenates and the hydrolysis of cellulose, was studied with X-ray diffraction (XRD) and magic angle spinning nuclear magnetic resonance spectroscopy (MAS-NMR) [14]. These techniques revealed the complete transformation of $\gamma-\mathrm{Al}_{2} \mathrm{O}_{3}$ within $10 \mathrm{~h}$ in water at 200 ${ }^{\circ} \mathrm{C}$ into hydrated boehmite $(\mathrm{AlOOH})$, the thermodynamically favored structure under these conditions (Fig. 1) [14,19]. The phase transition was accompanied by changes in specific surface area and surface acid-base properties. The authors also demonstrated that up to $40 \mathrm{ppm} \mathrm{Al}^{3+}$ leached into the reaction mixture depending on the platinum precursor used to synthesize $\mathrm{Pt} / \mathrm{Al}_{2} \mathrm{O}_{3}$ [20]. The leached species were catalytically active and a cellulose conversion of $42 \%$ with a glucose yield of $12 \%$ was achieved with only $30 \mathrm{ppm} \mathrm{Al}^{3+}$ in the solution [20].

Silica and ordered mesoporous silica (SBA-15, MCM-41, MCM-48) are among the least stable oxides in hot pressurized water. For example, the structure of SBA-15 collapsed within $12 \mathrm{~h}$ in water at $200{ }^{\circ} \mathrm{C}$ and 22 bar (autogenous pressure), resulting in a decrease of surface area from 740 to $30 \mathrm{~m}^{2} / \mathrm{g}$ [16]. The addition of aluminum to MCM-41 and SBA-15 improved stability in boiling water, but had little effect under harsher conditions [21]. The concentration of $\mathrm{H}^{+}$and $\mathrm{OH}^{-}$ions increases with temperature, which facilitates the acid- and base-cata-
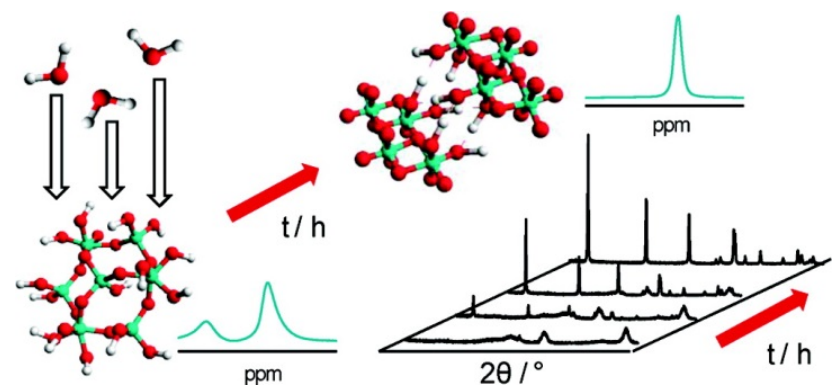

Fig. 1. NMR and XRD results demonstrating the phase transition of $\gamma-\mathrm{Al}_{2} \mathrm{O}_{3}$ to boehmite $(\mathrm{AlOOH})$ in liquid water at $200{ }^{\circ} \mathrm{C}$. Reprinted with permission from Ref. [14]. Copyright 2011 American Chemical Society. lyzed hydrolysis of $\mathrm{Si}-\mathrm{O}-\mathrm{Si}$ and $\mathrm{Si}-\mathrm{O}-\mathrm{Al}$ bonds [8,21]. Stability is also a challenge with zeolites, despite their crystalline structure. The stability of zeolites in liquid water at 150 and $200{ }^{\circ} \mathrm{C}$ was found to depend both on the zeolite framework type and $\mathrm{Si} / \mathrm{Al}$ ratio [8]. BEA, MOR, and Y zeolites were tested for the acid-catalyzed dehydration of fructose to 5-HMF $[17,18]$. In this work, $245 \mathrm{mg} / \mathrm{L}$ of dissolved $\mathrm{Si}$ and $\mathrm{Al}$ species were found after $5 \mathrm{~h}$ of aqueous phase reaction at $130{ }^{\circ} \mathrm{C}$, which represents $1-2$ wt $\%$ of the zeolite catalyst [18]. The dissolved species were shown to be catalytically active (Fig. 2). Currently, ZSM-5 seems to be the only zeolite stable under hydrothermal conditions $[8,22]$.

Other common metal oxide catalysts and catalyst supports include hydrotalcite, niobia, titania, and zirconia. Hydrotalcite degrades in the presence of organic acids even under mild conditions $\left(90^{\circ} \mathrm{C}\right)$, losing $70 \%$ of its $\mathrm{Mg}$ content within $20 \mathrm{~h}$ on stream [23]. Niobia supported catalysts tested for the conversion of $\gamma$-valerolactone to pentanoic acid in water experienced loss of surface area and metal sintering [24]. In contrast, titania and zirconia were stable under a broad range of reaction conditions [25,26].

These investigations made it clear that catalysts and catalysts supports initially developed for petrochemical reactions are unlikely to offer satisfactory long-term performance for the conversion of biomass in the condensed phase. As a result, designing heterogeneous catalysts structurally and chemically stable in green solvents such as water and alcohols is a prerequisite for the production of biorenewable chemicals. Over the past 5 years, significant work was carried out to synthesize active, selective, and stable heterogeneous catalysts. Up to now, interesting advancements in the field come from new classes of heterogeneous catalysts based on carbon as either an organic-inorganic hybrid or carbocatalyst [27].

\section{Organic-inorganic hybrids}

Different paths have been explored to improve the stability of oxides in hot liquid water. Mixed oxides gave promising results. The stability of silica can be improved by alumina or zir-

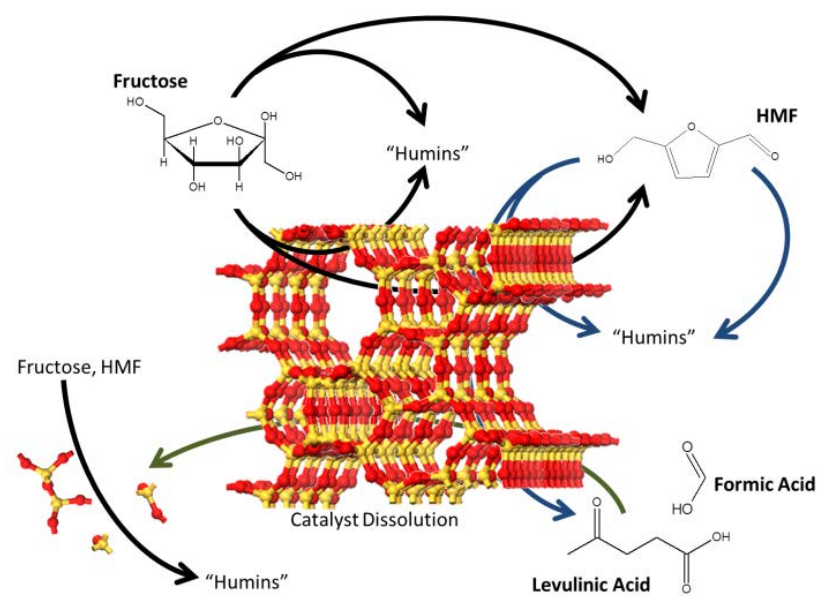

Fig. 2. Dehydration of fructose to HMF and its rehydration to formic and levulinic acids in aqueous systems catalyzed by zeolites and dissolved zeolite fragments. Reproduced with permission from Ref. [18]. 
conia doping [28]. In the case of niobia, the addition of $5 \mathrm{wt} \%$ silica stabilized the structure and prevented Pd nanoparticles from sintering [24]. More interestingly, the carbonaceous deposits formed under reaction conditions appeared to protect $\mathrm{Pt} / \gamma-\mathrm{Al}_{2} \mathrm{O}_{3}$ and $\mathrm{ZSM}-5$, the latter being stable even at a very high temperature $\left(400{ }^{\circ} \mathrm{C}\right)$ [22]. It appears that carbon is a promising candidate to passivate the surface and improve the stability of a large variety of oxides [22,29].

\subsection{Organosilane-grafted oxides}

Mesoporous silica, in particular SBA-15 functionalized with alkyl- and aryl-sulfonic acid groups, received increasing interest over the past decade. This organic-inorganic hybrid catalyst combines the high surface area and well-defined pore size of the SBA-15 with the opportunity to control the density and strength of the desired acid sites. The organic acids that are grafted using the surface hydroxyl groups ( $\mathrm{Si}-\mathrm{OH})$ as anchor points show stability in water at $100{ }^{\circ} \mathrm{C}$ for $24 \mathrm{~h}$ [30]. The high acidity and improved hydrothermal stability offers new options to heterogeneize reactions catalyzed by inorganic acids (e.g. $\mathrm{H}_{2} \mathrm{SO}_{4}$ ) and resins such as Amberlyst-15, which show instability at temperatures above $100{ }^{\circ} \mathrm{C}$. Alkyl sulfonic SBA-15 was tested for a variety of acid-catalyzed biomass conversion reactions, in particular for the production of biodiesel, the esterification of organic acids found in bio-oil, or the dehydration of fructose to 5-HMF [31-41]. Recycling tests and elemental analysis of the reaction medium confirmed that the catalysts are stable up to $130-140{ }^{\circ} \mathrm{C}[38,41]$. Interestingly, it was possible to tune the hydrophilic-hydrophobic character of the catalyst by grafting alkyl chains together with the desired sulfonic acid groups. The alkyl chains improved the water tolerance of the catalyst and shifted the esterification reaction equilibrium by repelling the produced water out of the SBA-15 channels [36,40].

Similarly, the stability of USY zeolite in water can be improved by grafting a high concentration of short alkyl chains [42]. As a result, alkyl groups cover all pockets and defects minimizing direct zeolite contact with the condensed phase [42]. Zapata et al. [42] demonstrated that hydrophobized HY zeolites can retain their crystallinity, surface area, microporosity, and acid site density in $200{ }^{\circ} \mathrm{C}$ liquid water while untreated HY zeolite collapses under the same conditions. HY zeolites hydrophobized with longer alkyl chains stabilize water/oil emulsions and catalyze reactions of importance in biofuel upgrading [43].

\subsection{Carbon-coated mesoporous oxides}

Silica has been used for over a decade as a template to synthesize novel carbon materials with controlled porosity [44-47]. The template is typically sacrificed to yield the exact inverse replica [44]. CMK-3, the carbon replica of SBA-15, has been used as a support for a variety of biomass conversion reactions $[48,49]$. In these studies, the authors built on carbons' high hydrothermal stability to design water-tolerant catalysts. More recently, Pham et al. [16] adopted a similar strategy to prevent the degradation of oxides in hot pressurized water by depositing a thin layer of carbon derived from sucrose onto the oxide surface (Fig. 3). This process has been successfully applied to commercial silica gel, fumed alumina, and mesoporous silica (SBA-15) for which the carbon layer was confirmed to coat the cylindrical pore wall. Solid-state NMR spectra revealed that the sucrose-derived carbon coating was composed of $75 \%$ aromatic carbon along with $25 \%$ alkyl chains and oxygen-containing functional groups. The hydrothermal stability of uncoated and $10 \mathrm{wt} \%$ carbon coated samples was investigated in liquid water at $200{ }^{\circ} \mathrm{C}$ for $12 \mathrm{~h}$ (Fig. 4). Carbon coated SBA-15 lost $55 \%$ of its specific surface area, which is a significant improvement compared to the $96 \%$ loss of the unmodified oxide. Uncoated silica gel and fumed alumina lost approximately $70 \%-75 \%$ of their surface area. In contrast, the coated oxides lost neither surface area nor structural integrity. Notably, $\gamma-\mathrm{Al}_{2} \mathrm{O}_{3}$ retained its structure, which is in good agreement with Ravenelle et al. [29] who observed that carbonaceous deposits (coke) that are formed under reaction conditions inhibit the transformation of $\gamma-\mathrm{Al}_{2} \mathrm{O}_{3}$ to hydrated boehmite.

\subsection{Carbon-metal oxide nanohybrids}

Various nanocarbon (nanotube, graphene)-transition metal oxide nanohybrids have been synthesized as heterogeneous catalysts for the selective oxidation of propane, the electrocatalytic conversion of $\mathrm{CO}_{2}$ to alcohols, and for the oxygen evolution reaction [50-55]. In all of these investigations, nanohybrids exhibited a higher performance and stability compared to the bulk oxide. Although the structured carbon supported catalysts typically observe a higher activity and stability than the corresponding bulk material, the interaction between the carbon support and the metal plays a crucial role in determining the performance of the catalysts. When coupling metals to a
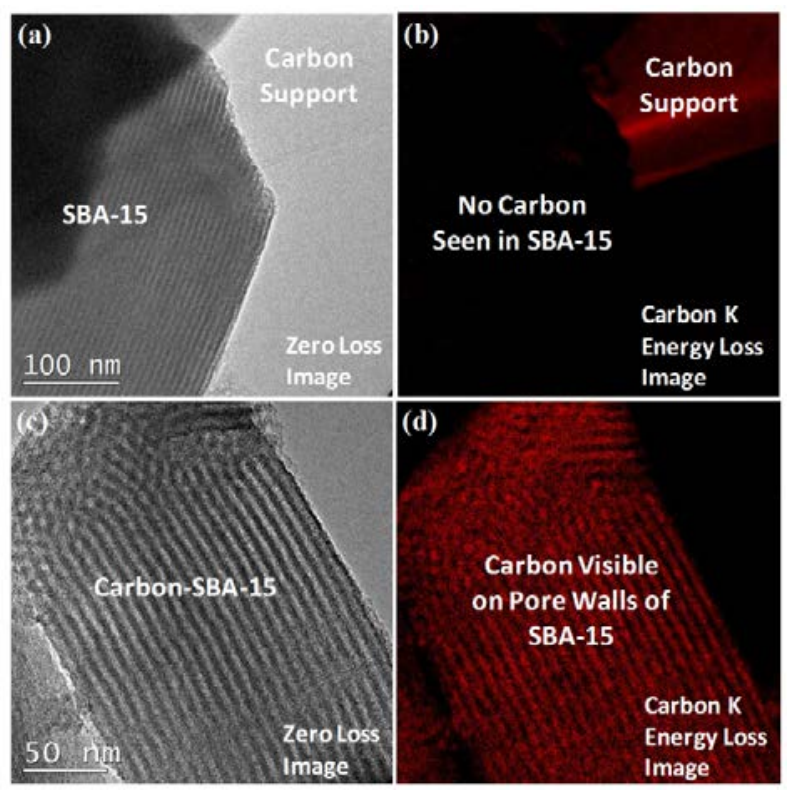

Fig. 3. HRTEM images of calcined SBA-15 (a) and $10 \mathrm{wt} \%$ carbonSBA-15 (c). The corresponding elemental carbon maps (b, d) reveal the homogenous coating of the $10 \mathrm{wt} \%$ carbon-SBA-15 pores (d). Reproduced with permission from Ref. [16]. 


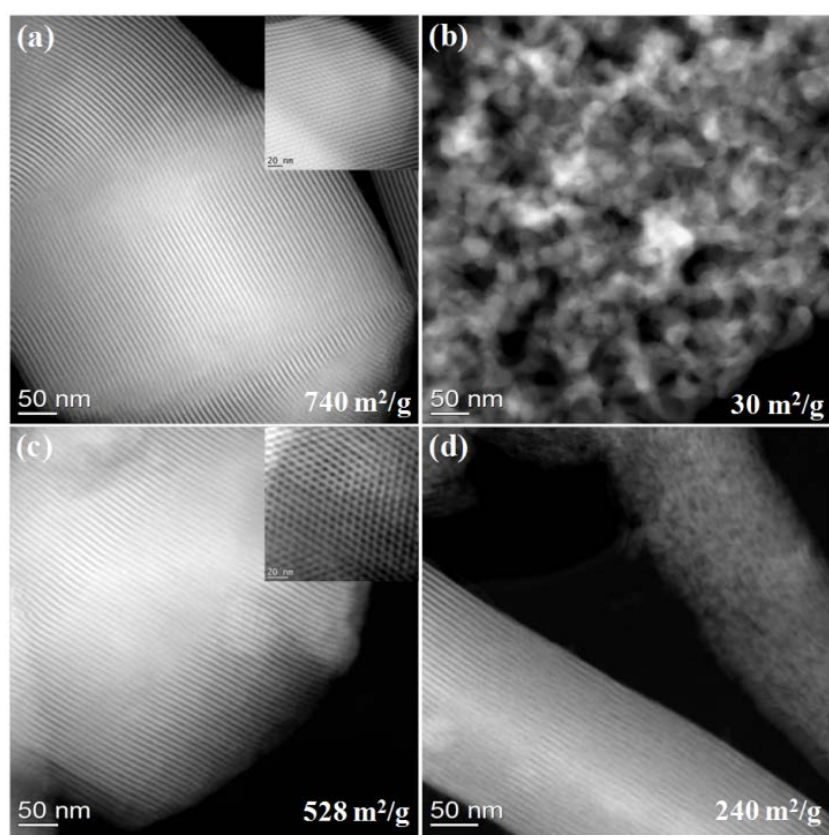

Fig. 4. STEM images of calcined SBA-15 (a, b) and $10 \mathrm{wt} \%$ carbonSBA-15 (c, d) with well-ordered hexagonal pores (insets). The calcined SBA-15 lost $96 \%$ of its surface area after treatment in liquid water at $473 \mathrm{~K}$ for $12 \mathrm{~h}$. In contrast, the carbon-coated SBA-15 was found to be more stable and it only lost $55 \%$ of its surface area. Reproduced with permission from Ref. [16].

structured carbon support by atomic layer deposition, the limited interactions associated with pristine basal plane inhibit functionalization [56]. As a result, oxidized carbon surfaces or $\pi-\pi$ interactions to the carbon support with functionality become a necessity to highly functionalize a pristine carbon surface [57]. It should be mentioned that a variety of interactions could take place with the carbon support, which can decrease or increase the catalysts stability and activity. Recent reports demonstrate carbons influence on a variety of carbon-metal oxide nanohybrids for biomass conversion reactions.

Liu et al. [58,59] investigated oxide stabilization for a $\mathrm{ZrO}_{2}$ catalyst supported on multiwalled carbon nanotubes. These nanohybrid catalysts were more stable in liquid water at $200{ }^{\circ} \mathrm{C}$ for $6 \mathrm{~h}$ than unsupported $\mathrm{ZrO}_{2}$. XRD and TEM images demonstrated that the particle size did not change from the initial 2.6 $\mathrm{nm}$ [58]. Near edge X-ray absorption fine structure spectroscopy (NEXAFS) revealed that the hydrothermal stability arises from strong interfacial interactions between $\mathrm{ZrO}_{2}$ and the MWCNT support [59]. The thermal stability changed inversely with particle size, thus indicating that oxygen-containing functional groups are used as anchoring points.

The Bitter group investigated the activity of hydrotalcite and nano-sized alkaline earth metal oxides supported on carbon nanofibers (CNFs) for the base-catalyzed transesterification and aldol condensation reactions [60,61]. The CNF-supported alkaline earth oxides were an order of magnitude more active than the corresponding bulk oxides. The difference in performance was explained by the high dispersion and large surface area of the oxide nanoparticles. For hydrotalcite, the supported nanoparticles were found to be more basic and the catalytic activity was 300 times higher than the bulk oxide [60]. CNFsupported catalysts were easier to regenerate and more stable than their unsupported oxide counterpart [61].

Resasco's group [62-67] developed a new class of amphiphilic organic-inorganic catalysts. These hybrids consist of oxide nanoparticles fused to carbon nanotubes. The obtained amphiphile stabilized water/oil emulsions and allowed reactions to take place at their interface (Fig. 5). The selective conversion of compounds present in one of the phases becomes possible by carefully controlling the deposition of metal nanoparticles on the oxide or the nanotube. MgO-Pd/CNT hybrids were used for the base-catalyzed aldol condensation of furfural with acetone followed by the hydrogenation of the products to $\mathrm{C}_{8}-\mathrm{C}_{10}$ fuel-range molecules [67]. The nanohybrids also showed a good activity for various hydrogenation, oxidation, and bio-oil upgrading reactions $[63,65,67]$.

Xiong et al. [68-70] studied the stability of niobia-carbon hybrids. Pure niobia crystallizes and deactivates quickly in liquid water at temperatures higher than $200{ }^{\circ} \mathrm{C}$, which is consistent with the results obtained for other oxides [24]. To prevent the deactivation, Xiong et al. [68] synthesized $\mathrm{Nb}_{2} \mathrm{O}_{5} / \mathrm{C}$ hybrids by impregnation, homogeneous deposition-precipitation (DP), and simultaneous deposition-precipitation-carbonization (DPC). Large niobia particles crystallized at $200{ }^{\circ} \mathrm{C}$ for the samples prepared by impregnation, due to the poor interaction with the carbon support. In contrast, the catalysts synthesized by DP were active and stable for over $40 \mathrm{~h}$ during the aqueous phase dehydration of 2-butanol to 1-butene at $240{ }^{\circ} \mathrm{C}$ and 52 bar.

\section{Functional carbons from carbohydrates}

Carbon plays a central role in stabilizing the structure and surface chemistry of oxides under hydrothermal conditions. Significant progress resulted from the design of organic-inorganic hybrids. However, in many cases it might be advantageous to design carbon-based catalysts. Over the past decade,

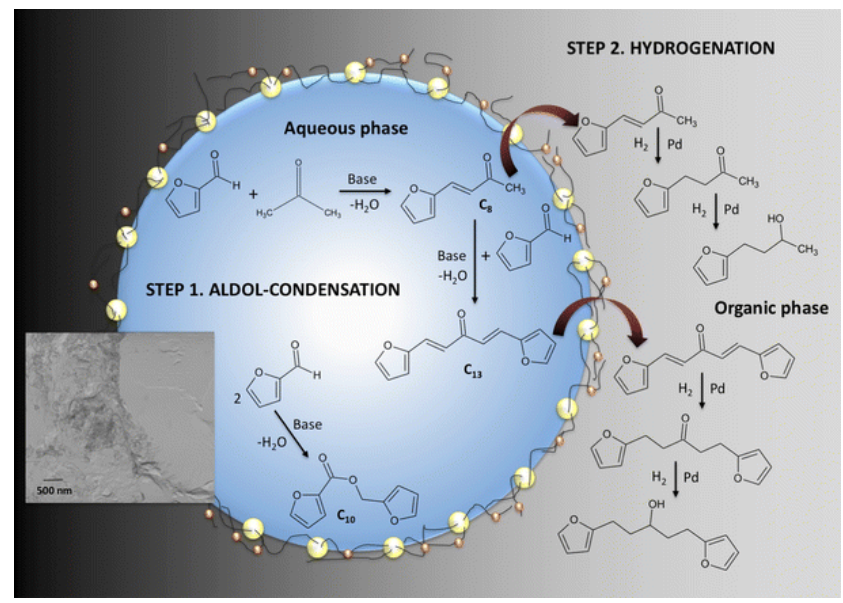

Fig. 5. One-pot base-catalyzed aldol condensation of furfural with acetone followed by the hydrogenation of the products to $\mathrm{C}_{8}-\mathrm{C}_{10}$ fuel-range molecules. The amphiphilic organic-inorganic catalyst stabilizes the water/oil emulsion. Reproduced with permission from Ref. [67] with kind permission from Springer Science and Business Media. 
several groups explored the potential to synthesize carbons directly from biomass-derived precursors by thermal and hydrothermal carbonization.

\subsection{Thermal carbonization}

Carbons produced from the thermal carbonization of aromatic compounds or carbohydrates such as cellulose and glucose are used for a variety of biomass conversion reactions. [71,72]. A general synthetic approach for the so-called "sugar catalyst" typically consists in the partial carbonization of the carbohydrate substrates through pyrolysis at $200-300{ }^{\circ} \mathrm{C}$ followed by refluxing with sulfuric acid to generate sulfonic functional groups [72-74]. The thermally carbonized material typically displays a surface area of less than $5 \mathrm{~m}^{2} / \mathrm{g}$ that is independent from the pyrolysis temperature and sulfonation conditions [74]. The produced carbons were reported to have a sheet-like structure containing 1.2-1.3 nm aromatic domains, structurally similar to graphene [74].

The sulfonated carbons were tested for various acid-catalyzed biomass conversion reactions including the hydrolysis of cellobiose, starch, and cellulose [75-80]. These carbons were also used for the esterification of long chain fatty acids and transesterification of triglycerides to produce biodiesel [74,81-83]. Despite the low surface area, the Cellulose-Derived Carbon Solid Acids (CCSA) exhibit a higher $-\mathrm{SO}_{3} \mathrm{H}$ loading, activity, and product yield when compared to commercially available solid acid catalysts, such as Amberlyst-15, Nafion, $\mathrm{H}$-mordenite, or niobic acid. Long term tests confirmed CCSA remains stable for $200 \mathrm{~h}$ on stream (Fig. 6) [74].

In addition to CCSA, sulfonated carbons with well-controlled porosity were synthesized using mesoporous templates such as SBA-15 or MCM-48. Sulfonated CMK-3 was used for the hydrolysis of cellulose and achieved a high cellulose conversion of $94.4 \%$ and glucose yield of $74.5 \%$ [49]. More recently, Chung et al. $[84,85]$ used MCM-48 nanoparticles prepared with a modified Stöber method as a template to synthesize sulfonated mesoporous carbon nanoparticles ( $\mathrm{HSO}_{3}-\mathrm{MCN}$ ).

Although high activities were reported for sulfonated car-
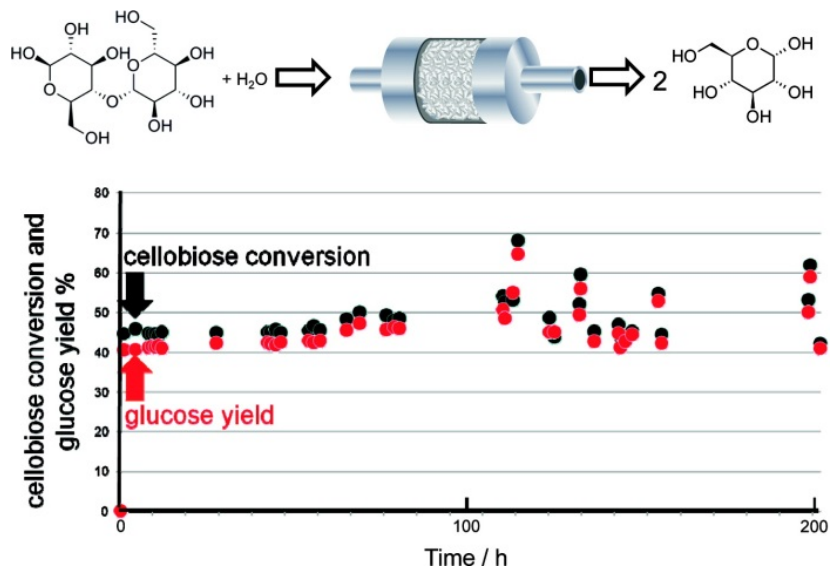

Fig. 6. CCSA-catalyzed hydrolysis of cellobiose in a fixed-bed reactor at 373 K. Reproduced with permission from Ref. [74]. Copyright 2012 American Chemical Society. bons under mild conditions, Anderson et al. [86] demonstrated using model compounds that the hydrothermal stability of sulfonic acid groups was a function of the local chemical environment. The stability was reported to follow the order of substituted aromatics < non-substituted aromatics < alkanes. For example, benzene sulfonic acid degraded in water at $160{ }^{\circ} \mathrm{C}$ within $24 \mathrm{~h}$ due to the reversibility of the aromatic sulfonation reaction. It appears that only sulfonic acid groups bonded to $s p^{3}$ carbon atoms are stable for extended periods of time under hydrothermal conditions [86]. Chung et al. [85] took advantage of this poor hydrothermal stability and designed a catalyst with $90 \%$ weak acid sites for the hydrolysis of Miscanthus xylan to xylose (Fig. 7). To synthesize this weak acid catalyst, $\mathrm{HSO}_{3}-\mathrm{MCN}$ was treated in water at $200{ }^{\circ} \mathrm{C}$ in order for a fraction of the sulfonic acid sites to leach. Catalytic tests showed the lack of direct proportional correlation between the hydrolysis rate and the acid site concentration. This finding suggested that the reaction mainly took place on sites with a high local concentration of acidic groups.

\subsection{Starch carbonization (Starbon $®$ )}

A synthetic approach that enables the production of mesoporous carbon materials with tunable surface chemistry from starch has been developed [87]. The reported template-free synthesis involves three steps (Fig. 8) and is another example of a biomass-derived carbon that can be used for biomass conversion:

1. Expansion: gelatization of starch in water to open and disorder the polymer network, followed by exchanging water with a low surface tension solvent (ethanol, acetone) to prevent the network structure from collapsing during the drying step

2. Drying: evaporation of the solvent to yield the mesoporous structured starch material

3. Pyrolysis: the starch material is doped with a catalytic amount of organic acid to promote carbonization and then heated under vacuum at 150 to $800{ }^{\circ} \mathrm{C}$

In this process, the carbons are free of any inorganic template, the porosity can be controlled through the gelation and carbonization steps, and the surface chemistry can be tuned

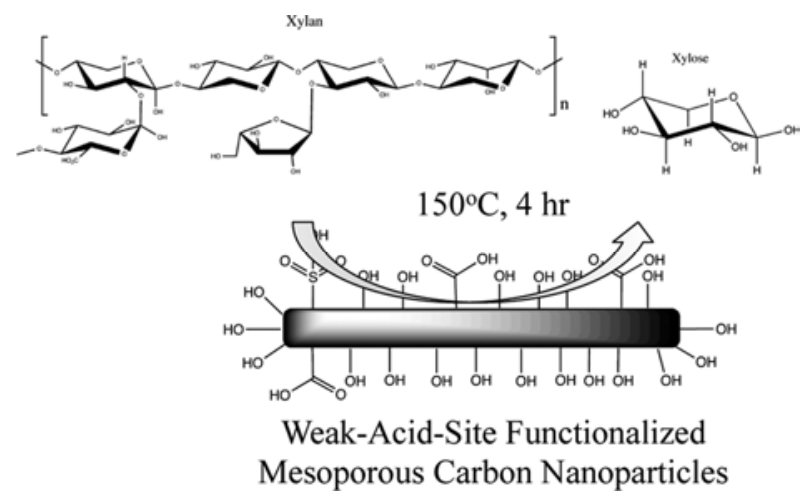

Fig. 7. Mesoporous carbon nanoparticles (MCN)-catalyzed hydrolysis of xylan to xylose. Reproduced with permission from Ref. [85]. Copyright 2014 American Chemical Society. 


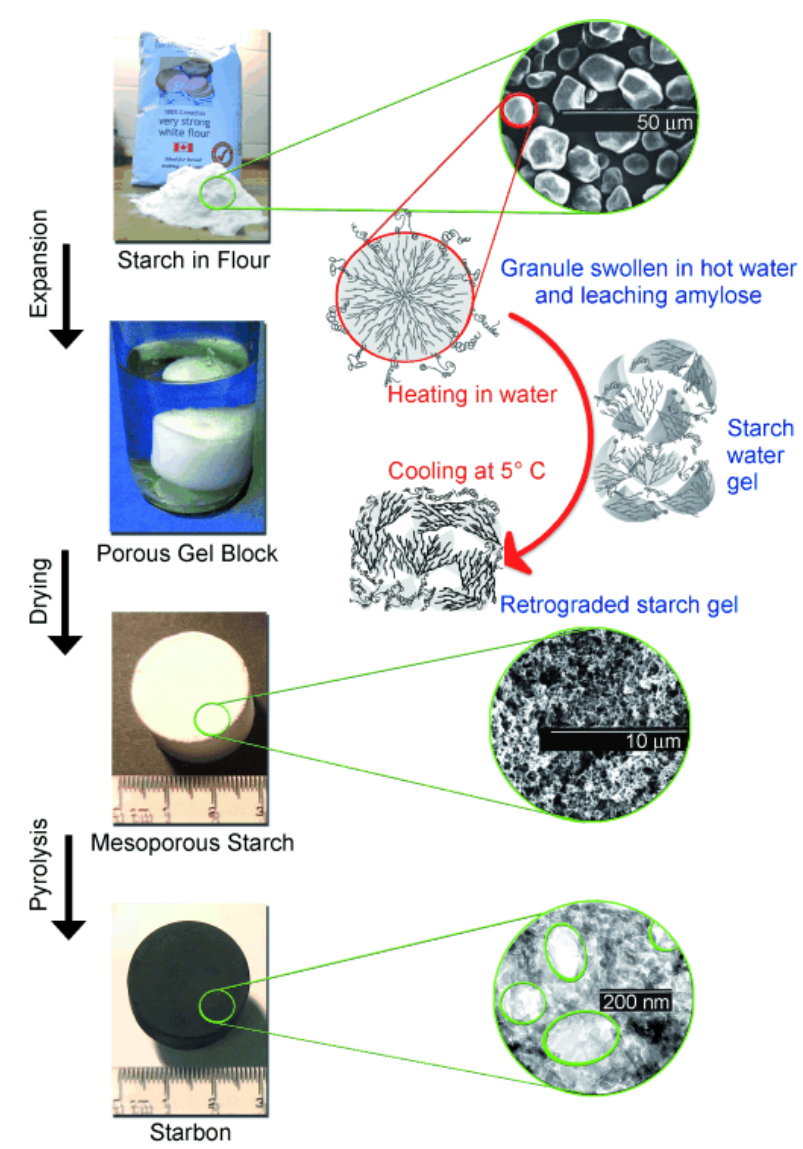

Fig. 8. Steps involved in the synthesis of mesoporous carbons from starch. Reproduced with permission from Ref. [87].

depending on the pyrolysis temperature (Fig. 9) [87-89]. The final product has a variable structure, stability, and chemistry that ranges from starch-like amorphous carbon to commercially available activated carbons [87]. The three-step carbonization process yields materials with high surface areas ranging from $150 \mathrm{~m}^{2} / \mathrm{g}$ to approximately $600 \mathrm{~m}^{2} / \mathrm{g}$ and pore sizes between 7 and $17 \mathrm{~nm}$ [90].

Depending on the synthesis procedure, these biomass-derived carbons have a wide range of applications that include the separation of polar analytes [91], $\mathrm{CO}_{2}$ capture [92], and heterogeneous catalysis [93-100]. Sulfonated starbons have catalyzed the esterification of succinic, fumaric, itaconic, and levulinic acids to their respective diesters in the presence of water $[93,94,96]$. They were shown to have a $>99 \%$ selectivity towards the desired diester products at a $>99 \%$ conversion within reasonable reaction time ( $8 \mathrm{~h}$ for succinic acid, $16 \mathrm{~h}$ for fumaric acid, and $6 \mathrm{~h}$ for levulinic acid), which outperformed zeolites and sulfated zirconia [94]. The activity and stability of sulfonated starbons varied with the temperature applied during the pyrolysis step; an optimum was found that possessed a balance between structural and chemical stability $[93,94]$. Reusability and hot filtration tests showed the starch-derived catalysts did not leach sulfur under reaction conditions [94].

In addition to being used as a catalyst, starbon has also been used as a support for the noble metal catalyzed hydrogeneation of succinic acid (Fig. 10) [98]. The carbons in this study were

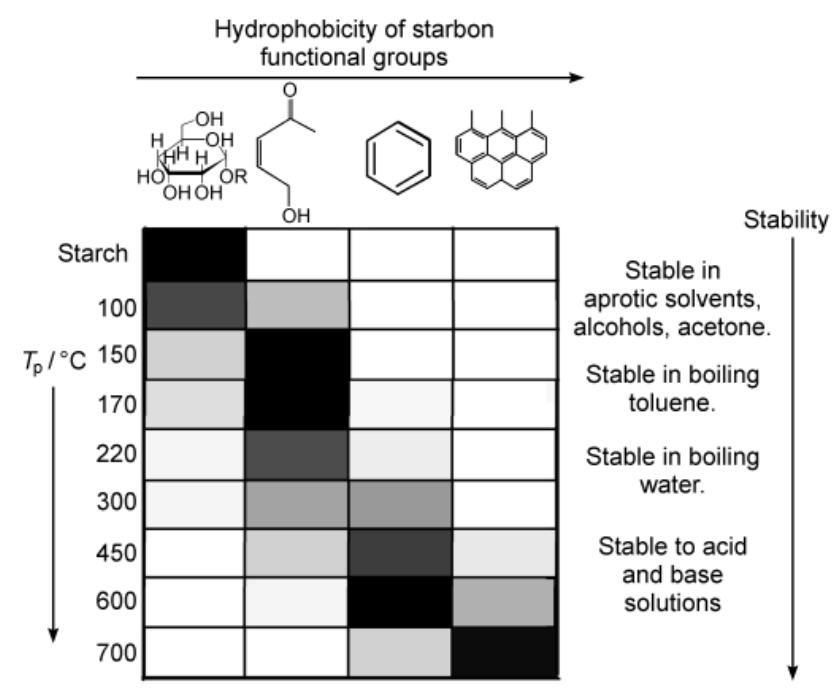

Fig. 9. Distribution of functional groups on starbons prepared at different temperatures: color scale to indicate relative amounts of different groups (black represents the highest). Reproduced with permission from Ref. [87].

pyrolyzed at $300{ }^{\circ} \mathrm{C}$ (Starbon-300) to exploit the hydrothermal stability and versatile surface chemistry [98-100]. Catalysts with $5 \mathrm{wt} \%$ of $\mathrm{Pd}, \mathrm{Pt}, \mathrm{Ru}$, and $\mathrm{Rh}$ were prepared by impregnation, reduced in $\mathrm{H}_{2}$, and tested for the hydrogenation of succinic acid in aqueous ethanol at 10 bar $\mathrm{H}_{2}$ and $100{ }^{\circ} \mathrm{C}$. Ru-Starbon300 presented the highest conversion (90\%) and selectivity (60\%) towards tetrahydrofuran, which can be used as either a precursor or a solvent for a large range of reactions. In contrast, Pt-Starbon-300 formed 1,4-butanediol with 78\% conversion and $85 \%$ selectivity. A more in-depth investigation was carried out to compare Starbon with commercially available activated carbons and carbon blacks (Norit, Vulcan, Darco) [100]. Overall, it was observed that the functionalized starch-derived carbon displayed a higher turnover frequency and stability compared to other commercially available carbons [100].

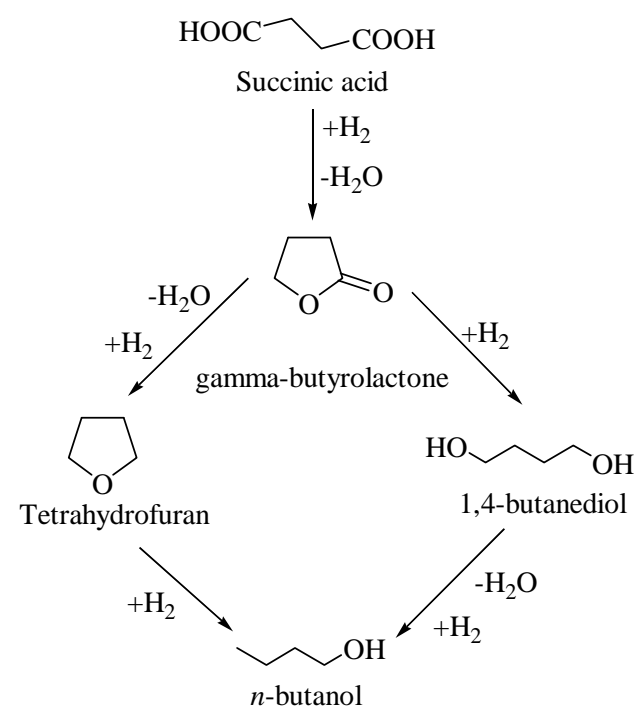

Fig. 10. Hydrogenation of succinic acid using supported metal nanoparticles on Starbon [98]. Adapted from Chemical Communications, 2009, 5307 with permission of the Royal Society of Chemistry. 


\subsection{Hydrothermal carbonization (HTC)}

Monodispersed carbon spheres were synthesized from sugars using pressurized water at $190{ }^{\circ} \mathrm{C}$ [101]. Hydrothermal carbonization offers several advantages over carbons produced by pyrolysis [102-117]:

1. The structure of the carbon backbone can be controlled by adjusting the reaction temperature (Fig. 11). Carbons made of interconnected furans form below $200{ }^{\circ} \mathrm{C}$, while higher temperatures favor more aromatic structures similar to those obtained by pyrolysis [118].

2. The morphology and porosity of the HTC carbons can be tailored using a template. For example, Tang et al. $[111,112]$ synthesized hollow nanospheres by carbonizing glucose around latex beads. The latex is removed after synthesis by thermal treatment at high temperature $\left(1000^{\circ} \mathrm{C}\right)$.

3. The surface chemistry can be finely adjusted by co-carbonizing glucose together with a precursor containing the desired functionality. The Titirici group tethered in separate works carboxylic acids [105], imidazole, amines, and sulfur-containing groups using acrylic acid, vinyl imidazole, glucosamine, and various amino acids $[108,109,113,114]$.

The materials synthesized by this approach were primarily used for the absorption of heavy metals [105], $\mathrm{CO}_{2}$ capture [108], and energy production and storage [109,111,112,114] However, interesting results were also obtained for applications in catalysis. Pd/HTC selectively hydrogenated various hydroxy aromatic derivatives (phenolics) to the corresponding saturated ketone. For example, phenol was converted to cyclohexanone. In contrast, commercial Pd/activated carbon yielded cyclohexanol [104]. The imidazole-functionalized HTC carbons also performed well for the Diels-Alder reaction, aldol condensation, and transesterification as model reactions relevant to the conversion of biomass [107]. Other recent progress on HTC carbons synthesis and future perspectives have been addressed in [118-120]. One promising development is the synthesis of

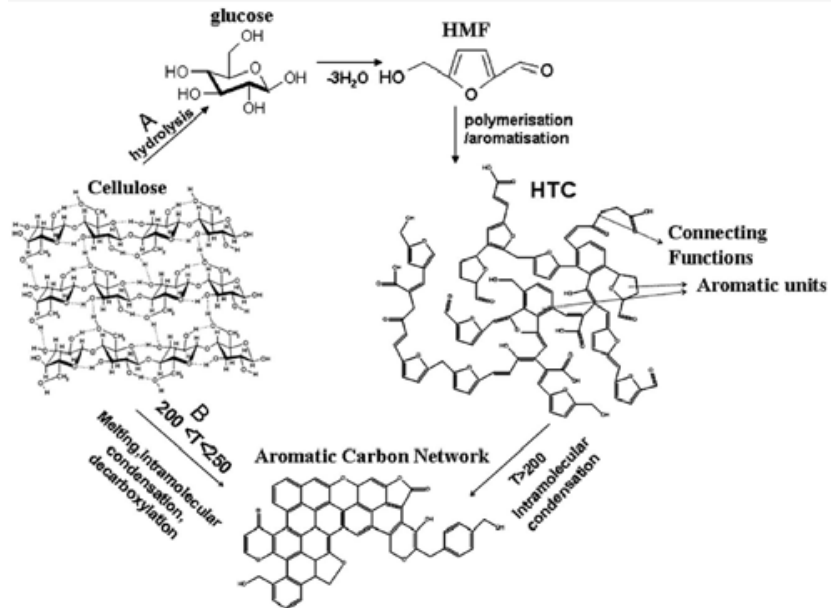

Fig. 11. Proposed mechanism for the conversion of cellulose to HTC: (a) via HMF or (b) by direct aromatization [118]. Reproduced from Energy \& Environmental Science, 2012, 6800 with permission of the Royal Society of Chemistry.
HTC-CNT composites, which combine the mechanical properties and high surface area of the nanotubes' aromatic backbone with HTC's high density of functional groups. Ming et al. [121] described this synthesis as "knitting an oxygenated network coat on the CNTs". Ru nanoparticles supported on HTC-CNT were highly dispersed $(0.9 \mathrm{~nm}$ instead of $1.8 \mathrm{~nm}$ on pristine CNTs) and were found to be more selective for the hydrogenation of citral.

Recently, Qi et al. [122] employed a similar strategy to synthesize amorphous carbons by hydrothermal carbonization of cellulose at $250{ }^{\circ} \mathrm{C}$ for $4 \mathrm{~h}$. The obtained carbons were further treated with $\mathrm{H}_{2} \mathrm{SO}_{4}$ at $200{ }^{\circ} \mathrm{C}$ to yield the desired carbonaceous sulfonated solid (CSS). CSS with a $-\mathrm{SO}_{3} \mathrm{H}$ concentration of 0.953 $\mathrm{mmol} / \mathrm{g}$ was tested for the dehydration of fructose to 5-HMF in ionic liquids. An $83 \%$ yield was obtained at $80{ }^{\circ} \mathrm{C}$ within $10 \mathrm{~min}$. In addition, the catalyst was stable for five successive cycles.

\section{Nanocarbon catalysts and catalyst supports}

The carbonization of biomass-derived carbohydrates offers interesting perspectives to design catalysts under mild and environmentally benign conditions. The hydrophilic-hydrophobic character, acid-base properties, porosity, and surface area can be tailored by adjusting the carbonization conditions. These materials are, however, heterogeneous at the nanoscale. FTIR, TGA, XPS, and NMR suggest the co-existence of a broad variety of oxygen-containing functional groups with different acid-base properties. In contrast, polymeric catalysts such as Nafion and Amberlyst-15 are structurally and chemically homogeneous, which is desired for the selective conversion of biomass. However, the resin backbone is fragile and can degrade at reaction temperatures above $80{ }^{\circ} \mathrm{C}$. Zhang et al. [123] synthesized a resin catalyst based on ligosulfonate co-condensed with phenol and formaldehyde. Lignosulfonate is a cheap waste stream from sulfite pulping during paper manufacturing $[123,124]$. The sulfonic acid catalysts were used in the hydrolysis of polysaccharides and other organic reactions. The resin-lignosulfonate catalyst was shown to be stable for four 6-h-cycles at $150{ }^{\circ} \mathrm{C}$ in water. However, hot filtration and additional recycling tests indicated a partial dissolution of the catalyst and leaching of the active sites into the reaction medium [123].

Nanotubes and graphene offer novel opportunities for catalysis. Specifically, structured carbons are well-defined, chemically stable in most aggressive media, and can be functionalized with organic and inorganic moieties $[125,126]$.

\subsection{Acid-base catalyzed reactions}

A variety of options are available to functionalize carbon surfaces. For example, sulfonated graphene was produced using the organic synthesis method depicted in Fig. 12 [127]. The obtained graphene- $\mathrm{SO}_{3} \mathrm{H}$ catalyzed the hydrolysis of ethyl acetate at $70{ }^{\circ} \mathrm{C}$. Recycling tests and elemental analysis confirmed that the catalyst was stable in water for at least 5 cycles.

Carbon nanotubes and nanofibers functionalized with 


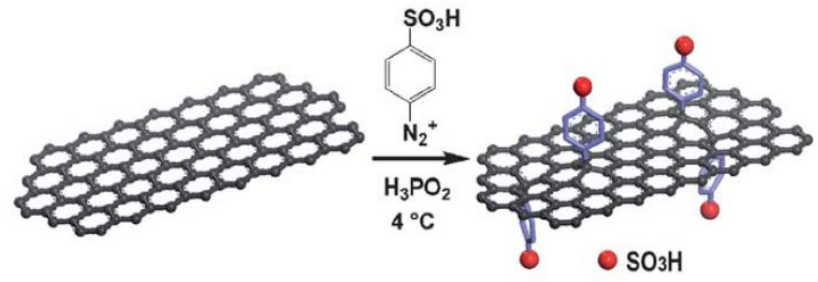

Fig. 12. Graphene sheet functionalization with aryl sulfonic acid groups [127]. Reproduced from Chemical Science, 2011, 484 with permission of the Royal Society of Chemistry.

$\operatorname{poly}(p$-styrenesulfonic acid) and benzenesulfonic acid groups were tested for the conversion of fructose to 5-HMF [128]. A linear correlation between acid site density and fructose conversion was observed. However, the catalytic activity dropped from $84 \%$ yield to $69 \%$ after 5 successive reactions at $120{ }^{\circ} \mathrm{C}$. This deactivation is consistent with the hydrothermal degradation of aryl sulfonic acids observed by Anderson et al. [86] and could be addressed by grafting alkyl sulfonic acid groups instead.

Organic chemistry techniques were also used to synthesize basic catalysts. For example, amino grafted nanotubes were produced by deprotonating CNTs with $n$-BuLi followed by an electrophilic substitution of bromo amino derivatives (triethylamine, ethylamine, pyrolidine) [129-131]. Active sites grafted by C-C coupling were significantly more active and stable for the transesterification of tributyrin than amino groups tethered by oxidation-amidation (Fig. 13). For the latter, the authors proposed that the coexistence of basic amino groups and acidic oxygen-containing functionality impairs the performance of the catalysts. In addition, the amide bonds were easily hydrolyzed under reaction conditions, as confirmed by ${ }^{1} \mathrm{H}$ NMR and elemental analysis of the reaction medium. Yuan et al. [132] synthesized amino-grafted graphene using the same

\section{Grafting by oxidation-amidation:}
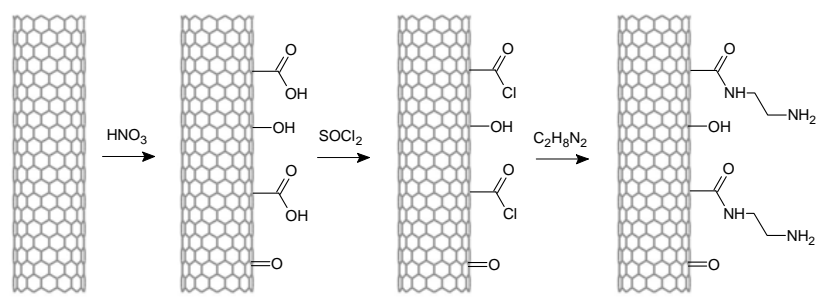

Grafting by electrophilic attack:
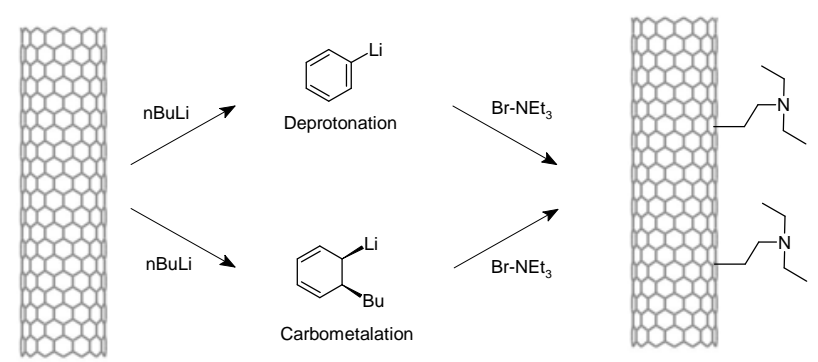

Fig. 13. Basic solid catalysts synthesized by oxidation-amidation and by electrophilic attack. Adapted from Ref. [129]. technique. NEt $\mathrm{N}_{3}$-graphene was almost twice more active than 1 $\mathrm{mol} / \mathrm{L} \mathrm{NaOH}$ when tested for the hydrolysis of ethyl acetate at $65^{\circ} \mathrm{C}$.

Acid-base functionalized nanocarbons received little attention for the conversion of lignocellulosic biomass compared to sulfonated CMK-3, Starbon, and HTC carbons. Typically, nanotubes, nanofibers, and graphene were used as catalyst supports for hydrogenation, hydrodeoxygenation, and selective oxidation reactions $[133,134]$.

\subsection{Hydrogenation and hydrogenolysis}

Carbon is the preferred support for a broad range of hydrogenation reactions due to stability and relative inertness under reaction conditions. Carbon-supported catalysts were employed for the hydrogenation of carbohydrates (glucose, fructose), furanics (5-HMF), and organic acids (succinic acid, levulinic acid, and lactic acid) [10]. Very high yields of 90\%-100\% are often observed using a noble metal active phase. For example, the hydrogenation of lactic acid to propylene glycol in aqueous solution can be carried out using $\mathrm{Pd}, \mathrm{Ru}$, $\mathrm{Ni}$, and $\mathrm{Cu}$ as catalysts [135]. Ru supported on activated carbon (Ru/AC) showed a high selectivity of $90 \%$ to propylene glycol at a 95\% conversion of lactic acid [135]. The effect of catalyst support on $\mathrm{Ru}$ activity was investigated using CNTs, CNFs, graphite, Vulcan XC-72, and Ketjen black [136]. The catalytic activity varied greatly with the catalyst support and the highest yield of propylene glycol was obtained with Ru on Ketjen black catalyst, primarily because of the higher dispersion obtained on this support.

Hydrogenolysis of glycerol to ethylene glycol and propylene glycol can be achieved using $\mathrm{Ru} / \mathrm{C}$ and $\mathrm{Pt} / \mathrm{C}$ catalysts $[137,138]$. Recently, $\mathrm{RuCu}$ and $\mathrm{RuCu}$ nanoparticles supported on CNTs showed $100 \%$ conversion and up to $75 \%$ selectivity towards glycols $[139,140]$.

Xylitol can also be converted into ethylene glycol and propylene glycol using $\mathrm{Ni} / \mathrm{C}$ catalyst in the presence of solid bases such as $\mathrm{CeO}_{2}$ and $\mathrm{Ca}(\mathrm{OH})_{2}$ [141]. Ni/C was reported to have a higher activity for this reaction as compared to $\mathrm{Ru} / \mathrm{C}$. In addition, it was possible to decrease the amount of base needed by supporting $\mathrm{Ni}$ on $\mathrm{CeO}_{2} / \mathrm{C}$ and $\mathrm{CaO} / \mathrm{C}$ hybrids.

Metal nanoparticles on carbon-based supports have been used for the depolymerization of cellulose by hydrogenolysis and by mechanocatalytic conversion [142,143]. Hydrogenation catalysts such as $\mathrm{Pt}, \mathrm{Ru}$, and $\mathrm{Pd}$ supported on carbons have been studied using a Design of Experiment approach [142]. It was observed that the metal used had an impact on the product and the nature of the reaction. $\mathrm{Pt} / \mathrm{C}$ and $\mathrm{Pd} / \mathrm{C}$ catalysts had a high conversion of cellulose to glucose and xylose. $\mathrm{Ru} / \mathrm{C}$, on the other hand, leads to the simple hydrolysis of cellulose to sugars first, followed by their hydrogenation to $\mathrm{C}_{4}-\mathrm{C}_{6}$ sugar alcohols. The mechanocatalytic approach combines mechanical ball milling with hydrogenolysis using $\mathrm{Ru} / \mathrm{C}$ catalysts for the production of sugar alcohols [143]. This approach yields up to $94 \%$ hexitol and it thereby provides a new direction for the depolymerizaton of biomass. Cellulose can also be converted to $\mathrm{C}_{2}-\mathrm{C}_{6}$ polyols by using $\mathrm{Ru} / \mathrm{CNT}$ as a catalyst in the presence of hy- 
drogen [144]. This conversion follows a two-step process during which acid-functionalized CNTs first hydrolyze cellulose into reducing sugars and $\mathrm{Ru}$ further hydrogenates them to sugar alcohols. Compared to $\mathrm{Fe}, \mathrm{Ni}, \mathrm{Co}, \mathrm{Pt}, \mathrm{Pd}, \mathrm{Rh}, \mathrm{Ir}, \mathrm{Ag}$, and $\mathrm{Au}$, $\mathrm{Ru}$ gave the highest yield of sorbitol from cellulose. CNT was also a more effective support than $\mathrm{SiO}_{2}, \mathrm{MgO}_{2} \mathrm{Al}_{2} \mathrm{O}_{3}$, and $\mathrm{CeO}_{2}$.

\subsection{Hydrodeoxygenation}

Defunctionalization reactions such as dehydration, decarboxylation/decarbonylation, and hydrodeoxygenation (HDO) play a central role in the conversion of over-functionalized carbohydrates to chemicals. Ideally, the HDO catalyst should favor $\mathrm{C}-\mathrm{O}$ over $\mathrm{C}-\mathrm{C}$ bond cleavage and preferentially produce unsaturated compounds to minimize $\mathrm{H}_{2}$ consumption [145]. Noble metals $(\mathrm{Pt})$ and transition metal carbides $\left(\mathrm{Mo}_{2} \mathrm{C}, \mathrm{WC}\right.$ $\mathrm{W}_{2} \mathrm{C}$ ) both catalyze HDO reactions $[145,146]$. $\mathrm{Mo}_{2} \mathrm{C}$ exhibits a high selectivity towards $\mathrm{C}-\mathrm{O} / \mathrm{C}=0$ cleavage with negligible $\mathrm{C}-\mathrm{C}$ bond scission. Therefore, $\mathrm{Mo}_{2} \mathrm{C}$ received increasing attention over the past few years for the HDO of vegetable oils, $\mathrm{C}_{3}$ oxygenates, lignin-derivatives, and others [145-153]. Several groups dispersed $\mathrm{Mo}_{2} \mathrm{C}$ on activated carbon [147], Ordered Mesoporous Carbon (OMC) [149], CNTs [148], and CNFs [150-153]. Oxygen-containing functional groups on the surface of carbon serve as anchoring points to the Mo precursor. A high dispersion is typically observed on carbons oxidized with nitric acid (Fig. 14) [148]. The carbon support also offers the possibility to form $\mathrm{Mo}_{2} \mathrm{C}$ by carbothermal reduction using the carbon atoms of the support $[148,152]$. This technique simplifies the catalyst synthesis as additional carburization using alkanes is no longer needed. This creates chemical bonds at the carbide-support interface that improve the catalysts stability. Compared to $\mathrm{Mo} 2 \mathrm{C} / \mathrm{AC}$ and $\mathrm{Mo}_{2} \mathrm{C} / \mathrm{CNT}, \mathrm{Mo}_{2} \mathrm{C} / \mathrm{CNF}$ did not produce any branched hydrocarbons during the HDO of vege-
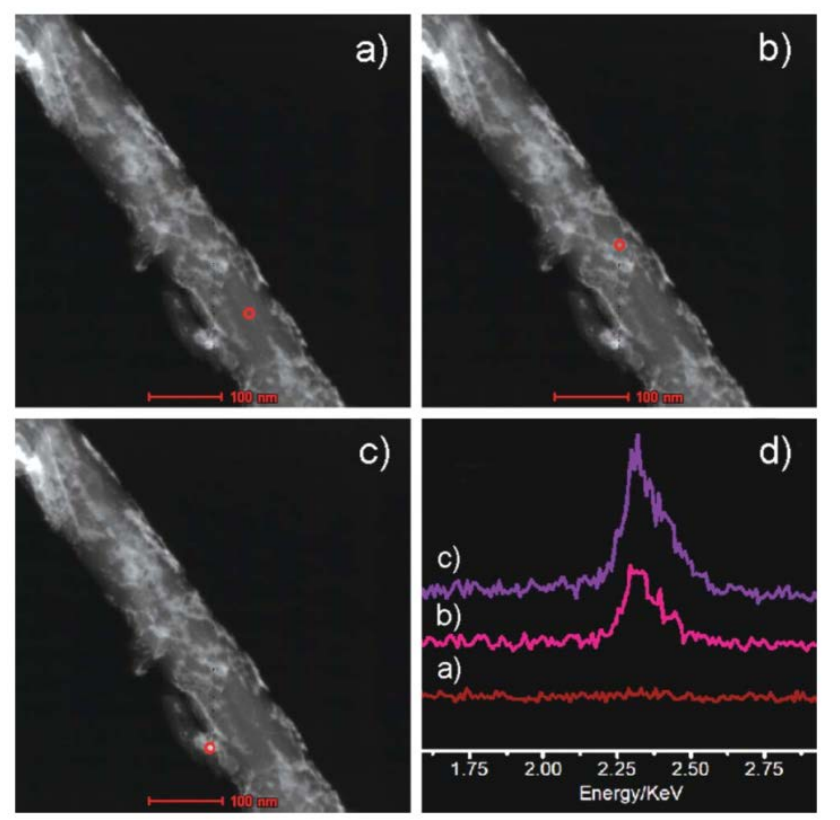

Fig. 14. STEM-HAADF images (a-c) and EDX spot analysis (d) of a $\mathrm{Mo}_{2} \mathrm{C} / \mathrm{CNT}$ catalyst [148]. Reproduced from Green Chemistry, 2011, 2563 with permission of the Royal Society of Chemistry. table oils to high-grade diesel fuels, which indicates the structure of the support may play additional roles in the reaction that remain to be elucidated [153].

\subsection{Selective oxidation}

Selective oxidation is a key reaction to introduce desired functionalities in biomass-derived compounds [154]. Relevant reactions include the oxidation of 5-HMF to 2,5-furandicarboxylic acid (FDCA), glycerol to glyceric acid, and cellobiose to gluconic acid. Davis et al. [154] recently reviewed current progress in this field. Selective oxidation reactions are catalyzed by noble metals such as $\mathrm{Pd}, \mathrm{Pt}, \mathrm{Au}$, and their alloys (PdAu, PtAu). Carbon was selected as a support in many works due to its stability in both acidic and basic media [154-156].

The role of the nanocarbon's surface on the particle size and shape of Au nanoparticles was studied by Gil et. al. The study determined supports with few structural defects such as graphite and ribbon carbon nanofibers stabilize Au significantly better than fishbone and platelet nanofibers that offer a prismatic surface to the nanoparticles (i.e. edges) $[157,158]$. Catalysts with graphitic supports were more selective towards glyceric acid and gave higher turnover frequencies. Similarly, Rodriguez et al. [159] studied Au supported on CNTs with different levels of surface oxygen-containing groups. Au supported on oxidized CNTs was significantly less active and less selective towards glyceric acid. Notably, acidic functional groups favored the formation of glycolic acid, an unwanted over-functionalized side product.

$\mathrm{Au} / \mathrm{CNT}$ catalysts have also demonstrated potential for the selective oxidation of cellobiose to gluconic acid in aqueous medium [160]. A significant difference in gluconic acid yield was observed when varying the support. Au supported on Vulcan XC-72 and graphite showed a 50\% conversion and $\sim 30 \%$ selectivity towards the desired product. In comparison, $\mathrm{Au} / \mathrm{CNT}$ offered $60 \%$ selectivity towards gluconic acid at $90 \%$ conversion of cellobiose [160]. Tan et al. demonstrated that acidic oxygen-containing functional groups play an active role in the hydrolysis of cellobiose to glucose, which is an intermediate for this reaction, followed by $\mathrm{Au}$ catalyzed oxidation to gluconic acid.

$\mathrm{Pd}, \mathrm{Pt}, \mathrm{Au}$ and their alloys supported on activated carbon, CNF, CNT, and graphite were also studied for the selective oxidation of 5-HMF to 5-hydroxymethyl-2-furancarboxylic acid (HFCA) and FDCA (Fig. 15) [161]. The selectivity to FDCA varies between $6 \%$ and $80 \%$ depending on the nature and oxygen content of the carbon support. The least functionalized supports (CNT, graphite) were more selective towards HFCA, while the most oxidized product, FDCA, was obtained with Au/activated carbon.

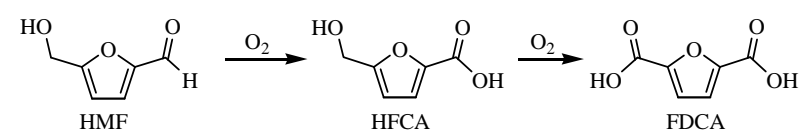

Fig. 15. Reaction steps involved in the conversion of HMF to FDCA. A correlation exists for $\mathrm{Au} / \mathrm{C}$ catalysts between the selectivity to FDCA and the surface chemistry of the carbon support. Adapted from Ref. [161]. 


\section{Summary and outlook}

New challenges emerge in heterogeneous catalysis with the production of chemicals from bio-renewables. Most reactions take place in the condensed phase, typically in water above the normal boiling point. Therefore, it becomes critical to synthesize catalysts structurally and chemically stable under these conditions. Significant progress was achieved by designing novel organic-inorganic hybrids as well as carbon-based and carbon-supported catalysts.

Oxides that undergo phase transitions and/or leach under reaction conditions were stabilized by coating the surface with alkyl chains or with a thin carbon film. In a later development, novel nanohybrids were obtained by tethering oxide nanoparticles to the surface of CNTs/CNFs or inside a carbon matrix obtained by co-carbonization. In all cases, the oxides' intrinsic catalytic properties remained unaltered while carbon provided hydrothermal stability to the nanohybrid. At the same time, carbon-based catalysts were synthesized to yield hydrothermally stable catalysts with chemical flexibility. Carbons synthesized from carbohydrates showed, upon sulfonation, a high activity for a broad range of acid-catalyzed reactions. However, carbons from carbohydrates are intrinsically heterogeneous in structure and surface chemistry. The heterogeneous nature makes them unsuitable for more complex reactions that require well-defined active sites at the atomic scale to achieve high selectivity. Alternatively, well-defined nanocarbons such as graphene, CNFs, and CNTs open new routes to design hydrothermally stable catalysts with tailored surface properties. For example, it was possible to tune the selectivity of Au/CNT towards HFCA or FDCA by adjusting the acid-base character and oxygen content of the CNT support.

While significant advances were made in designing carbon-based hydrothermally stable catalysts, work was primarily focused on the mesoscale properties. To rationally design catalysts that target specific reactions, advanced characterization techniques become necessary to provide a new level of chemical, morphological, and structural understanding.

Aberration-corrected TEM and STEM provided information on the catalyst structure at the atomic scale. The carbon support was found to strongly influence the shape of supported $\mathrm{Au}$ nanoparticles (Fig. 16), from nearly spherical on disordered supports to highly faceted on more graphitic carbons [162]. Significant differences in selectivity were observed for the oxidation of glycerol. Spherical Au particles yielded glyceric acid, while faceted $\mathrm{Au}$ favored $\mathrm{C}-\mathrm{C}$ bond cleavage to form glycolic and formic acids. In the case of $\mathrm{Au}$, the surface topology and interfacial energy seem to dictate the shape of the supported particles. Similar effects on particle shape were observed for Pd when varying the acid-base character of the surface by functionalization with 0 or $\mathrm{N}$ containing groups [163]. In general, the interaction with the $\mathrm{N}$-containing functional groups promotes the catalytic activity of the metal [164-166].

Aberration-corrected TEM combined with in situ XRD and in situ XPS also demonstrated that carbon atoms from defective supports could diffuse into $\mathrm{Ni}$ and $\mathrm{Pd}$ nanoparticles to form non-stoichiometric carbides $\left(\mathrm{NiC}_{x}, \mathrm{PdC}_{x}\right)[167,168]$. In the case
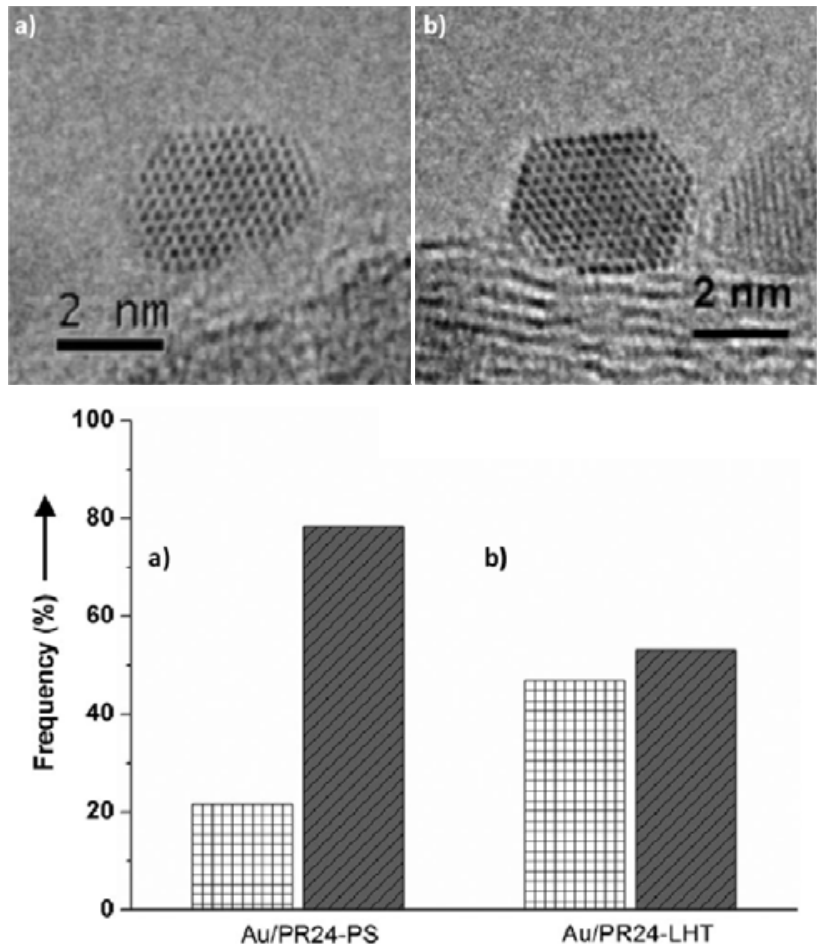

Fig. 16. Aberration-corrected images of Au supported on defective (a) and graphitic carbon supports (b). The histogram shows the distribution of particles with (111) planes parallel to the carbon surface (white), and particles with other orientation (black). Adapted from Ref. [162].

of $\mathrm{PdC}_{x}$, a high selectivity was observed for the conversion of acetylene to ethylene compared to a $\mathrm{Pd} / \mathrm{Al}_{2} \mathrm{O}_{3}$ catalyst [166]. Notably, carbide formation occurs in flowing $\mathrm{H}_{2}$ between 120 and $300{ }^{\circ} \mathrm{C}$, conditions often employed when synthesizing catalysts.

Significant efforts were also dedicated to improving the understanding of nanocarbon's structure and chemistry. Recent progress in solid state NMR delivered models for the structure of graphene oxide and carbons synthesized from carbohydrates [169-174]. The distribution of nitrogen atoms in CNTs were mapped at the nanoscale using energy-filtered TEM tomography (Fig. 17) [175]. HRTEM also revealed that topological defects and vacancies cluster to yield a patchwork structure made of defect-free graphene areas with sizes of a few nanometers interspersed with defect areas [176,177].
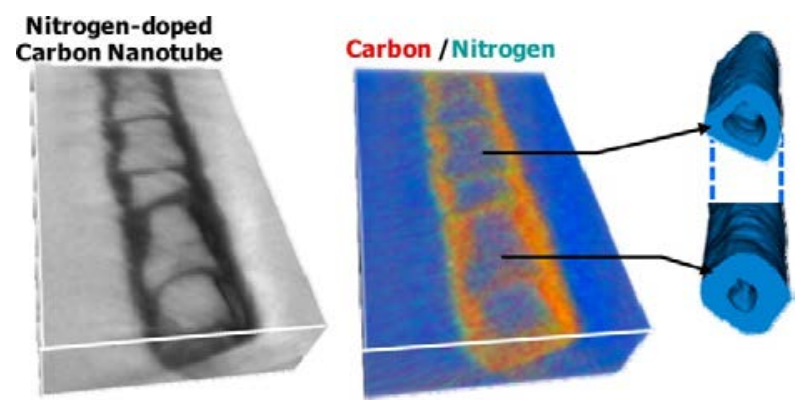

Fig. 17. Longitudinal slice of the reconstructed N-doped CNT (left) with the corresponding 3D elemental map (right). Reproduced with permission from Ref. [175]. Copyright 2012 American Chemical Society. 
Investigating catalysts under reaction conditions constitute the next major challenge to overcome. Time resolved in situ XPS [178-180] and TEM [181,182] will provide critical information on dynamic changes in catalyst structure and chemistry depending on chemical potential. This information coupled with theoretical calculations [183] will lead to the next generation of carbocatalysts and carbon-supported catalysts for the selective conversion of biomass to renewable chemicals in the condensed phase.

\section{Acknowledgments}

This work was supported by the National Science Foundation under NSF Grant Number EEC-0813570, and by the Iowa Energy Center under IEC Grant Number 13-01. Research at the Ames Laboratory was supported by the U.S. Department of Energy-Laboratory Royalty Revenue through Contract No. DE-AC02-07CH11358. CP would also like to thank the Ames Laboratory for providing a Fellowship through the U.S. Department of Energy Office of Science's Science Undergraduate Laboratory Internship (SULI).

\section{References}

[1] Bozell J J, Petersen G R. Green Chem, 2010, 12: 539

[2] Shanks B H. Ind Eng Chem Res, 2010, 49: 10212

[3] Wang K, Kim K H, Brown R C. Green Chem, 2014, 16: 727

[4] López D E, Goodwin J G Jr, Bruce D A, Lotero E. Appl Catal A, 2005, 295: 97

[5] Liu Y J, Lotero E, Goodwin J G Jr, Lu C Q.J Catal, 2007, 246: 428

[6] Xi Y Z, Davis R J. J Catal, 2008, 254: 190

[7] Xi Y Z, Davis R J. J Catal, 2009, 268: 307

[8] Ravenelle R M, Schüßler F, D’Amico A, Danilina N, van Bokhoven J A, Lercher J A, Jones C W, Sievers C. J Phys Chem C, 2010, 114: 19582

[9] van Putten R-J, van der Waal J C, de Jong E, Rasrendra C B, Heeres H J, de Vries J G. Chem Rev, 2013, 113: 1499

[10] Besson M, Gallezot P, Pinel C. Chem Rev, 2013, 114: 1827

[11] Jin F, Enomoto H. Energy Environ Sci, 2011, 4: 382

[12] Yabushita M, Kobayashi H, Fukuoka A. Appl Catal B, 2014, 145: 1

[13] Kobayashi H, Fukuoka A. Green Chem, 2013, 15: 1740

[14] Ravenelle R M, Copeland J R, Kim W-G, Crittenden J C, Sievers C. ACS Catal, 2011, 1: 552

[15] Lanzl C A, Baltrusaitis J, Cwiertny D M. Langmuir, 2012, 28: 15797
[16] Pham H N, Anderson A E, Johnson R L, Schmidt-Rohr K, Datye A K. Angew Chem Int Ed, 2012, 51: 13163

[17] Kruger J S, Choudhary V, Nikolakis V, Vlachos D G. ACS Catal, 2013, 3: 1279

[18] Kruger J S, Nikolakis V, Vlachos D G. Appl Catal A, 2014, 469: 116

[19] Koichumanova K, Vikla A K K, de Vlieger D J M, Seshan K, Mojet B L, Lefferts L. ChemSusChem, 2013, 6: 1717

[20] Ravenelle R M, Diallo F Z, Crittenden J C, Sievers C. ChemCatChem, 2012, 4: 492

[21] Pollock R A, Gor G Y, Walsh B R, Fry J, Ghampson I T, Melnichenko Y B, Kaiser H, DeSisto W J, Wheeler M C, Frederick B G.J Phys Chem C, 2012, 116: 22802

[22] Mo N, Savage P E. ACS Sus Chem Eng, 2013, 2: 88

[23] Zope B N, Davis S E, Davis R J. Top Catal, 2012, 55: 24

[24] Pham H N, Pagan-Torres Y J, Serrano-Ruiz J C, Wang D, Dumesic J A, Datye A K. Appl Catal A, 2011, 397: 153

[25] Delgado S N, Yap D, Vivier L, Especel C. J Mol Catal A, 2013, 367: 89

[26] Yadav G D, Nair J J. Microporous Mesoporous Mater, 1999, 33: 1

[27] Su C, Loh K P. Acc Chem Res, 2013, 46: 2275

[28] Bore M T, Marzke R F, Ward T L, Datye A K. J Mater Chem, 2005, 15: 5022

[29] Ravenelle R M, Copeland J R, van Pelt A H, Crittenden J C, Sievers C. Top Catal, 2012, 55: 162

[30] Margolese D, Melero J A, Christiansen S C, Chmelka B F, Stucky G D. Chem Mater, 2000, 12: 2448

[31] Mbaraka I K, Radu D R, Lin V S Y, Shanks B H. J Catal, 2003, 219: 329

[32] Mbaraka I K, Shanks B H.J Catal, 2005, 229: 365

[33] Mbaraka I K, Shanks B H. J Catal, 2006, 244: 78

[34] Bootsma J A, Shanks B H. Appl Catal A, 2007, 327: 44

[35] Bootsma J A, Entorf M, Eder J, Shanks B H. Bioresour Technol, 2008, 99: 5226

[36] Miao S, Shanks B H. Appl Catal A, 2009, 359: 113

[37] Dhainaut J, Dacquin J-P, Lee A F, Wilson K. Green Chem, 2010, 12: 296

[38] Melero J A, Bautista L F, Morales G, Iglesias J, Sánchez-Vázquez R. Chem Eng J, 2010, 161: 323

[39] Crisci A J, Tucker M H, Lee M-Y, Jang S G, Dumesic J A, Scott S L. ACS Catal, 2011, 1: 719

[40] Tsai C-H, Chen H-T, Althaus S M, Mao K, Kobayashi T, Pruski M, Lin V S Y. ACS Catal, 2011, 1: 729

[41] Tucker M H, Crisci A J, Wigington B N, Phadke N, Alamillo R, Zhang J, Scott S L, Dumesic J A. ACS Catal, 2012, 2: 1865

[42] Zapata P A, Huang Y, Gonzalez-Borja M A, Resasco D E. J Catal, 2013, 308: 82

\section{Graphical Abstract}

Chin. J. Catal., 2014, 35: 842-855 doi: 10.1016/S1872-2067(14)60122-4 Functional carbons and carbon nanohybrids for the catalytic conversion
of biomass to renewable chemicals in the condensed phase

John Matthiesen, Thomas Hoff, Chi Liu, Charles Pueschel, Radhika Rao, Jean-Philippe Tessonnier*

Iowa State University, USA; NSF-ERC Center for Biorenewable Chemicals (CBiRC), USA; US Department of Energy Ames Laboratory, USA

The transition between petrochemistry and biorenewable chemistry challenges the catalysts figures of merit, in particular the catalysts stability. This review addresses recent advances to design catalysts for the liquid-phase conversion of biomass to chemicals.

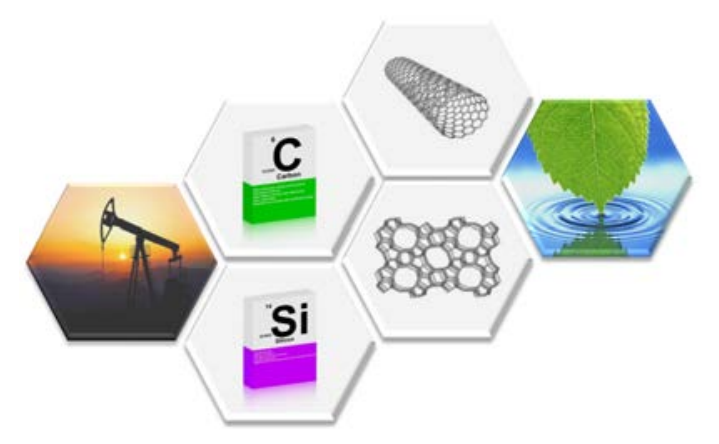


[43] Zapata P A, Faria J, Ruiz M P, Jentoft R E, Resasco D E. J Am Chem Soc, 2012, 134: 8570

[44] Ryoo R, Joo S H, Jun S. J Phys Chem B, 1999, 103: 7743

[45] Jun S, Joo S H, Ryoo R, Kruk M, Jaroniec M, Liu Z, Ohsuna T, Terasaki O.J Am Chem Soc, 2000, 122: 10712

[46] Yu J-S, Kang S, Yoon S B, Chai G.J Am Chem Soc, 2002, 124: 9382

[47] Choi M, Ryoo R. Nat Mater, 2003, 2: 473

[48] Kobayashi H, Komanoya T, Hara K, Fukuoka A. ChemSusChem, 2010, 3: 440

[49] Pang J F, Wang A Q, Zheng M Y, Zhang T. Chem Commun, 2010, 46: 6935

[50] Ressler T, Walter A, Scholz J, Tessonnier J-P, Su D S. J Catal, 2010, 271: 305

[51] Arrigo R, Schuster M E, Wrabetz S, Girgsdies F, Tessonnier J-P, Centi G, Perathoner S, Su D S, Schlögl R. ChemSusChem, 2012, 5: 577

[52] Marichy C, Tessonnier J-P, Ferro M C, Lee K-H, Schlögl R, Pinna N, Willinger M-G.J Mater Chem, 2012, 22: 7323

[53] Mette K, Bergmann A, Tessonnier J-P, Hävecker M, Ressler T, Schlögl R, Strasser P, Behrens M. ChemCatChem, 2012, 4: 851

[54] Tessonnier J-P, Goubert-Renaudin S, Alia S, Yan Y, Barteau M A. Langmuir, 2013, 29: 393

[55] Marichy C, Russo P A, Latino M, Tessonnier J-P, Willinger M-G, Donato N, Neri G, Pinna N. J Phys Chem C, 2013, 117: 19729

[56] Wang X R, Tabakman S M, Dai H J.J Am Chem Soc, 2008, 130: 8152

[57] Liang Y Y, Li Y G, Wang H L, Dai H J. J Am Chem Soc, 2013, 135: 2013

[58] Liu C C, Lee S, Su D, Lee B, Lee S, Winans R E, Yin C, Vajda S, Pfefferle L, Haller G L. Langmuir, 2012, 28: 17159

[59] Liu C C, Lee S, Su D, Zhang Z T, Pfefferle L, Haller G L. J Phys Chem C, 2012, 116: 21742

[60] Álvarez M G, Frey A M, Bitter J H, Segarra A M, de Jong K P, Medina F. Appl Catal B, 2013, 134-135: 231

[61] Frey A M, Yang J, Feche C, Essayem N, Stellwagen D R, Figueras F, de Jong K P, Bitter J H. J Catal, 2013, 305: 1

[62] Shen M, Resasco D E. Langmuir, 2009, 25: 10843

[63] Crossley S, Faria J, Shen M, Resasco D E. Science, 2010, 327: 68

[64] Faria J, Ruiz M P, Resasco D E. Adv Synth Catal, 2010, 352: 2359

[65] Ruiz M P, Faria J, Shen M, Drexler S, Prasomsri T, Resasco D E. ChemSusChem, 2011, 4: 964

[66] Drexler S, Faria J, Ruiz M P, Harwell J H, Resasco D E. Energy Fuels, 2012, 26: 2231

[67] Zapata P A, Faria J, Pilar Ruiz M, Resasco D E. Top Catal, 2012, 55: 38

[68] Xiong H F, Nolan M, Shanks B H, Datye A K. Appl Catal A, 2014, 471: 165

[69] Xiong H F, Pham H N, Datye A K. J Catal, 2013, 302: 93

[70] Xiong H F, Wang T F, Shanks B H, Datye A K. Catal Lett, 2013, 143: 509

[71] Hara M, Yoshida T, Takagaki A, Takata T, Kondo J N, Hayashi S, Domen K. Angew Chem Int Ed, 2004, 43: 2955

[72] Toda M, Takagaki A, Okamura M, Kondo J N, Hayashi S, Domen K, Hara M. Nature, 2005, 438: 178

[73] Okamura M, Takagaki A, Toda M, Kondo J N, Domen K, Tatsumi T, Hara M, Hayashi S. Chem Mater, 2006, 18: 3039

[74] Nakajima K, Hara M. ACS Catal, 2012, 2: 1296

[75] Suganuma S, Nakajima K, Kitano M, Yamaguchi D, Kato H, Hayashi S, Hara M. J Am Chem Soc, 2008, 130: 12787

[76] Suganuma S, Nakajima K, Kitano M, Yamaguchi D, Kato H, Hayashi S, Hara M. Solid State Sci, 2010, 12: 1029

[77] Yamaguchi D, Kitano M, Suganuma S, Nakajima K, Kato H, Hara M. J Phys Chem C, 2009, 113: 3181
[78] Yamaguchi D, Hara M. Solid State Sci, 2010, 12: 1018

[79] Kitano M, Yamaguchi D, Suganuma S, Nakajima K, Kato H, Hayashi S, Hara M. Langmuir, 2009, 25: 5068

[80] Suganuma S, Nakajima K, Kitano M, Hayashi S, Hara M. Chemsuschem, 2012, 5: 1841

[81] Takagaki A, Toda M, Okamura M, Kondo J N, Hayashi S, Domen K, Hara M. Catal Today, 2006, 116: 157

[82] Hara M. ChemSusChem, 2009, 2: 129

[83] Hara M. Top Catal, 2010, 53: 805

[84] Chung P-W, Charmot A, Gazit O M, Katz A. Langmuir, 2012, 28: 15222

[85] Chung P-W, Charmot A, Olatunji-Ojo O A, Durkin K A, Katz A. ACS Catal, 2014, 4: 302

[86] Anderson J M, Johnson R L, Schmidt-Rohr K, Shanks B H. Catal Commun, 2014, 51: 33

[87] Budarin V, Clark J H, Hardy J J E, Luque R, Milkowski K, Tavener S J, Wilson A J. Angew Chem Int Ed, 2006, 45: 3782

[88] Shuttleworth P S, Budarin V, White R J, Gun'ko V M, Luque R, Clark J H. Chem Eur J, 2013, 19: 9351

[89] White R J, Budarin V L, Clark J H. ChemSusChem, 2008, 1: 408

[90] White R J, Budarin V, Luque R, Clark J H, Macquarrie D J. Chem Soc Rev, 2009, 38: 3401

[91] White R J, Antonio C, Budarin V L, Bergstrom E, Thomas-Oates J, Clark J H. Adv Funct Mater, 2010, 20: 1834

[92] Hunt A J, Sin E H K, Marriott R, Clark J H. ChemSusChem, 2010, 3: 306

[93] Budarin V, Luque R, Macquarrie D J, Clark J H. Chem Eur J, 2007, 13: 6914

[94] Budarin V L, Clark J H, Luque R, Macquarrie D J. Chem Commun, 2007: 634

[95] Budarin V L, Clark J H, Luque R, Macquarrie D J, White R J. Green Chem, 2008, 10: 382

[96] Clark J H, Budarin V, Dugmore T, Luque R, Macquarrie D J, Strelko V. Catal Commun, 2008, 9: 1709

[97] Luque R, Budarin V, Clark J H, Macquarrie D J. Green Chem, 2009, 11: 459

[98] Luque R, Clark J H, Yoshida K, Gai P L. Chem Commun, 2009: 5305

[99] White R J, Luque R, Budarin V L, Clark J H, Macquarrie D J. Chem Soc Rev, 2009, 38: 481

[100] Luque R, Clark J H. Catal Commun, 2010, 11: 928

[101] Wang Q, Li H, Chen L Q, Huang X J. Carbon, 2001, 39: 2211

[102] Titirici M M, Thomas A, Antonietti M. Adv Funct Mater, 2007, 17: 1010

[103] Titirici M M, Thomas A, Antonietti M. J Mater Chem, 2007, 17: 3412

[104] Makowski P, Cakan R D, Antonietti M, Goettmann F, Titirici M M. Chem Commun, 2008: 999

[105] Demir-Cakan R, Baccile N, Antonietti M, Titirici M M. Chem Mater, 2009, 21: 484

[106] White R J, Antonietti M, Titirici M M. J Mater Chem, 2009, 19: 8645

[107] Demir-Cakan R, Makowski P, Antonietti M, Goettmann F, Titirici M M. Catal Today, 2010, 150: 115

[108] Zhao L, Bacsik Z, Hedin N, Wei W, Sun Y H, Antonietti M, Titirici M M. ChemSusChem, 2010, 3: 840

[109] Zhao L, Fan L Z, Zhou M Q, Guan H, Qiao S Y, Antonietti M, Titirici M M. Adv Mater, 2010, 22: 5202

[110] White R J, Yoshizawa N, Antonietti M, Titirici M M. Green Chem, 2011, 13: 2428

[111] Tang K, Fu L J, White R J, Yu L H, Titirici M M, Antonietti M, Maier J. Adv Energy Mater, 2012, 2: 873

[112] Tang K, White R J, Mu X K, Titirici M M, van Aken P A, Maier J. 
ChemSusChem, 2012, 5: 400

[113] Wohlgemuth S A, Vilela F, Titirici M M, Antonietti M. Green Chem, 2012, 14: 741

[114] Wohlgemuth S A, White R J, Willinger M G, Titirici M M, Antonietti M. Green Chem, 2012, 14: 1515

[115] Sevilla M, Yu L H, Fellinger T P, Fuertes A B, Titirici M M. RSC Adv, 2013, 3: 9904

[116] Yu L H, Brun N, Sakaushi K, Eckert J, Titirici M M. Carbon, 2013, 61: 245

[117] Brun N, Sakaushi K, Eckert J, Titirici M M. ACS Sus Chem Eng, 2014, 2: 126

[118] Titirici M M, White R J, Falco C, Sevilla M. Energy Environ Sci, 2012, 5: 6796

[119] Hu B, Wang K, Wu L H, Yu S H, Antonietti M, Titirici M M. Adv Mater, 2010, 22: 813

[120] Funke A, Ziegler F. Biofuels Bioprod Bioref, 2010, 4: 160

[121] Ming J, Liu R X, Liang G F, Cheng H Y, Yu Y C, Zhao F Y.J Mater Chem, 2011, 21: 10929

[122] Qi X H, Guo H X, Li L Y, Smith R L. Chemsuschem, 2012, 5: 2215

[123] Zhang X C, Zhang Z, Wang F, Wang Y H, Song Q, Xu J.J Mol Catal A, 2013, 377: 102

[124] Sun S H, Bai R X, Gu Y L. Chem Eur J, 2014, 20: 549

[125] Su D S, Perathoner S, Centi G. Chem Rev, 2013, 113: 5782

[126] Zhu J, Holmen A, Chen D. ChemCatChem, 2013, 5: 378

[127] Ji J Y, Zhang G H, Chen H Y, Wang S L, Zhang G L, Zhang F B, Fan X B. Chem Sci, 2011, 2: 484

[128] Liu R L, Chen J Z, Huang X, Chen L M, Ma L L, Li X J. Green Chem, 2013, 15: 2895

[129] Tessonnier J-P, Villa A, Majoulet O, Su D S, Schlögl R. Angew Chem Int Ed, 2009, 48: 6543

[130] Villa A, Tessonnier J-P, Majoulet O, Su D S, Schlögl R. Chem Commun, 2009: 4405

[131] Villa A, Tessonnier J-P, Majoulet O, Su D S, Schlögl R. ChemSusChem, 2010, 3: 241

[132] Yuan C F, Chen W F, Yan L F. J Mater Chem, 2012, 22: 7456

[133] Wang A, Li C, Zheng M, Zhang T. In: Hoboken N J Ed. The Role of Green Chemistry in Biomass Processing and Conversion. USA: John Wiley \& Sons, Inc., 2012. 313

[134] Wang H J, Zhu L L, Peng S, Peng F, Yu H, Yang J. Renew Energy, 2012, 37: 192

[135] Zhang Z G, Jackson J E, Miller D J. Appl Catal A, 2001, 219: 89

[136] Jang H, Kim S-H, Lee D, Shim S E, Baeck S-H, Kim B S, Chang T S.J Mol Catal A, 2013, 380: 57

[137] Lahr D G, Shanks B H. J Catal, 2005, 232: 386

[138] Maris E P, Davis R J. J Catal, 2007, 249: 328

[139] Li B D, Wang J, Yuan Y Z, Ariga H, Takakusagi S, Asakura K. ACS Catal, 2011, 1: 1521

[140] Wu Z J, Mao Y Z, Wang X X, Zhang M H. Green Chem, 2011, 13: 1311

[141] Sun J, Liu H. Catal Today, 2014, in press

[142] Palkovits R, Tajvidi K, Procelewska J, Rinaldi R, Ruppert A. Green Chem, 2010, 12: 972

[143] Hilgert J, Meine N, Rinaldi R, Schüth F. Energy Environ Sci, 2013, 6: 92

[144] Deng W P, Tan X S, Fang W H, Zhang Q H, Wang Y. Catal Lett, 2009, 133: 167

[145] Ren H, Yu W T, Salciccioli M, Chen Y, Huang Y L, Xiong K, Vlachos D G, Chen J G. ChemSusChem, 2013, 6: 798

[146] Ren H, Chen Y, Huang Y L, Deng W H, Vlachos D G, Chen J G. Green Chem, 2014, 16: 761

[147] Han J X, Duan J Z, Chen P, Lou H, Zheng X M. Adv Synth Catal, 2011, 353: 2577
[148] Han J X, Duan J Z, Chen P, Lou H, Zheng X M, Hong H P. Green Chem, 2011, 13: 2561

[149] Han J X, Duan J Z, Chen P, Lou H, Zheng X M, Hong H P. ChemSusChem, 2012, 5: 727

[150] Gosselink R W, Stellwagen D R, Bitter J H. Angew Chem Int Ed, 2013, 52: 5089

[151] Jongerius A L, Bruijnincx P C A, Weckhuysen B M. Green Chem, 2013, 15: 3049

[152] Jongerius A L, Gosselink R W, Dijkstra J, Bitter J H, Bruijnincx P C A, Weckhuysen B M. ChemCatChem, 2013, 5: 2964

[153] Qin Y, Chen P, Duan J Z, Han J X, Lou H, Zheng X M, Hong H P. RSC $A d v, 2013,3: 17485$

[154] Davis S E, Ide M S, Davis R J. Green Chem, 2013, 15: 17

[155] Guo Z, Liu B, Zhang Q H, Deng W P, Wang Y, Yang Y H. Chem Soc Rev, 2014, 43: 3480

[156] Prati L, Villa A, Lupini A R, Veith G M. Phys Chem Chem Phys, 2012, 14: 2969

[157] Gil S, Muñoz L, Sánchez-Silva L, Romero A, Valverde J L. Chem Eng J, 2011, 172: 418

[158] Gil S, Marchena M, Fernández C M, Sánchez-Silva L, Romero A, Valverde J L. Appl Catal A, 2013, 450: 189

[159] Rodrigues E G, Delgado J J, Chen X, Pereira M F R, Órfão J J M. Ind Eng Chem Res, 2012, 51: 15884

[160] Tan X S, Deng W P, Liu M, Zhang Q H, Wang Y. Chem Commun 2009: 7179

[161] Villa A, Schiavoni M, Campisi S, Veith G M, Prati L. ChemSusChem, 2013, 6: 609

[162] Wang D, Villa A, Su D S, Prati L, Schlögl R. ChemCatChem, 2013, 5: 2717

[163] Arrigo R, Wrabetz S, Schuster M E, Wang D, Villa A, Rosenthal D, Girsgdies F, Weinberg G, Prati L, Schlögl R, Su D S. Phys Chem Chem Phys, 2012, 14: 10523

[164] Chizari K, Janowska I, Houllé M, Florea I, Ersen 0, Romero T, Bernhardt P, Ledoux M J, Pham-Huu C. Appl Catal A, 2010, 380: 72

[165] Chen P P, Chew L M, Kostka A, Muhler M, Xia W. Catal Sci Technol, 2013, 3: 1964

[166] Chen P R, Yang F K, Kostka A, Xia W. ACS Catal, 2014, 4: 1478

[167] Rinaldi A, Tessonnier J-P, Schuster M E, Blume R, Girgsdies F, Zhang Q Jacob T, Abd Hamid S B, Su D S, Schlögl R. Angew Chem Int $E d, 2011,50: 3313$

[168] Shao L D, Zhang B S, Zhang W, Teschner D, Girgsdies F, Schlögl R, Su D S. Chem Eur J, 2012, 18: 14962

[169] Lerf A, He H, Forster M, Klinowski J. J Phys Chem B, 1998, 102: 4477

[170] Szabó T, Berkesi O, Forgó P, Josepovits K, Sanakis Y, Petridis D, Dékány I. Chem Mater, 2006, 18: 2740

[171] Baccile N, Laurent G, Coelho C, Babonneau F, Zhao L, Titirici M M. J Phys Chem C, 2011, 115: 8976

[172] Engtrakul C, Irurzun V M, Gjersing E L, Holt J M, Larsen B A, Resasco D E, Blackburn J L. J Am Chem Soc, 2012, 134: 4850

[173] Johnson R L, Anderson J M, Shanks B H, Fang X, Hong M, Schmidt-Rohr K. J Magn Reson, 2013, 234: 112

[174] Johnson R L, Schmidt-Rohr K. J Magn Reson, 2014, 239: 44

[175] Florea I, Ersen O, Arenal R, Ihiawakrim D, Messaoudi C, Chizari K, Janowska I, Pham-Huu C. J Am Chem Soc, 2012, 134: 9672

[176] Gómez-Navarro C, Meyer J C, Sundaram R S, Chuvilin A, Kurasch S, Burghard M, Kern K, Kaiser U. Nano Lett, 2010, 10: 1144

[177] Guo J J, Morris J R, Ihm Y, Contescu C I, Gallego N C, Duscher G, Pennycook S J, Chisholm M F. Small, 2012, 8: 3283

[178] Knop-Gericke A, Kleimenov E, Hävecker M, Blume R, Teschner D, Zafeiratos S, Schlögl R, Bukhtiyarov V I, Kaichev V V, Prosvirin I 
P, Nizovskii A I, Bluhm H, Barinov A, Dudin P, Kiskinova M. Adv Catal, 2009, 52: 213

[179] Arrigo R, Havecker M, Schlögl R, Su D S. Chem Commun, 2008: 4891

[180] Arrigo R, Hävecker M, Wrabetz S, Blume R, Lerch M, McGregor J, Parrott E P J, Zeitler J A, Gladden L F, Knop-Gericke A, Schlögl R,
Su D S. J Am Chem Soc, 2010, 132: 9616

[181] Grunwaldt J-D, Wagner J B, Dunin-Borkowski R E. ChemCatChem, 2013, 5: 62

[182] Zhang B S, Su D S. Small, 2014, 10: 222

[183] Gao W, Mueller J E, Anton J, Jiang Q, Jacob T. Angew Chem Int Ed, 2013, 52: 14237 